\title{
Democracia e Legitimidade: três teses sobre o papel da comunicação na justificação política
}

Renato Francisquini

\section{Resumo}

Este trabalho pretende contribuir para uma compreensão abrangente sobre o papel atribuído à comunicação, pela teoria democrática contemporânea, na justificação da autoridade política. Para realizar esse objetivo, as diversas perspectivas teóricas serão agrupadas em três rubricas - as teses da contribuição, da exclusividade e da necessidade - segundo o lugar conferido por elas à deliberação pública na garantia da legitimidade das decisões coletivas. A partir de uma revisão da literatura pertinente, evidencia-se uma distinção no que se refere às condições suficientes el ou necessárias para que as decisões políticas sejam consideradas por todos os afetados como moralmente aceitáveis e politicamente convenientes. Resta claro, destarte, uma discordância de fundo nessas perspectivas no que tange ao grau de importância assinalado à comunicação entre iguais para assegurar a justificação da autoridade política.

Palavras-chave: Teoria democrática. Legitimidade. Comunicação.

\section{Introdução}

A democracia é, por sua natureza, um sistema em que se veda a imposiçáo de decisôes vinculantes aos cidadáos (DAHL, 2006). Uma das principais preocupaçóes da teoria democrática, nesse sentido, é a de identificar as razōes que poderiam ser mobilizadas para assegurar o consentimento, o qual se sustenta na convicção dos cidadãos que estáo submetidos às regras e decisóes de que estas são moralmente defensáveis e politicamente

\footnotetext{
I Professor Adjunto do Departamento de Ciência Política da Universidade Federal da Bahia (UFBA).

E-mail: renato.francisquini@ufba.br
}

\section{$(\infty))$ EY}

Direito autoral e licença de uso: Este artigo está licenciado sob uma Licença Creative Commons. Com essa licença você pode compartilhar, adaptar, para qualquer fim, desde que atribua a autoria da obra, forneça um link para a licença, e indicar se foram feitas alterações. 
convenientes. Descarta-se, como razão plausível, entre outras coisas, o recurso à violência ou à ameaça de coerção, que desconstrói a capacidade do poder de reivindicar obediência. A legitimidade de um arranjo político e de suas decisóes - que envolvem eventualmente o emprego da coerção física - depende de que sejam justificáveis aos cidadãos sobre os quais reivindicam autoridade.

A teoria democrática, todavia, compreende de maneiras distintas as razóes que levam os que se submetem à estrutura institucional a aceitar as normas propaladas e a sua execução pelo aparato político. Essa questão, veja-se, não se refere à gênese histórica da estrutura institucional vigente, mas, antes, à justificação das restrições impostas por tal estrutura, isto é, às formas de autoridade que nela se constituem. Em regimes democráticos, a legitimidade está associada à possibilidade de se justificar as decisóes coletivas e o emprego do aparato coercitivo do Estado. Justificação, esta, que se sustenta em certas razóes que são capazes de reivindicar o consentimento dos cidadãos.

Em oposição à tese, de viés hobbesiano, que considera que a autoridade legítima consiste em uma abdicação justificada da faculdade do julgamento em favor do soberano representante, a tradição democrática sustenta que os cidadáos mantêm a prerrogativa do julgamento com respeito às decisôes políticas e à sua implementação. A capacidade de julgamento, nessa tradição, identifica-se com a ideia de soberania popular, que remete a certos elementos práticos, como os mecanismos de decisão majoritários, a garantia dos direitos individuais associados à participação no autogoverno e os procedimentos deliberativos presentes nas democracias contemporâneas (WARREN, 1996, p. 46).

A ideia de legitimidade guarda uma relação direta com a informação disponível à fundamentação de nossas decisôes e com a possibilidade de livre comunicação entre os cidadãos. No trabalho que ora se introduz, discuto diferentes maneiras de se olhar para o papel da comunicação na justificação das decisôes políticas e da autoridade democrática. Vou me orientar, neste trabalho, por uma ideia de comunicação entendida lato sensu 
como discussão pública². Compreendo a comunicação pública como um intercâmbio multifacetado e diversificado de discursos, argumentos, razôes e opiniôes, uma troca que ocorre nas inúmeras esferas públicas e entre estas e os fóruns formais do Estado. A relação entre comunicação e democracia não deve ser entendida apenas como o engajamento simultâneo, de um número qualquer de pessoas, sob uma estrutura institucional específica. Como sugere Chambers, “[...] estudar a deliberação como um fenômeno de massas significa falar sobre fenômenos, isto é, significa generalizar sobre formas múltiplas, plurais e sobrepostas de discurso político dispostas no tempo e no espaço" (2012, p. 54) . $^{3}$

Na democracia, a comunicação é uma atividade essencialmente prática. Isso significa que a comunicação pública se orienta pela busca de respostas para questôes acerca "do que deve ser feito", sobre "quem somos", "como nos relacionamos com o outro" e "que tipo de sociedade queremos". As práticas comunicativas envolvem, assim, o oferecimento, a recepção e a avaliação de razôes a favor ou contra um curso de ação, os fundamentos das relaçôes entre as pessoas e a nossa própria compreensão de nós mesmos e do mundo (CHAMBERS, 2012) ${ }^{4}$.

Chambers (2012, p. 56-59) distingue "deliberação" de "discussão", sugerindo que a primeira recorre necessariamente a razóes, enquanto a última pode se restringir a uma reunião de opinióes. Contudo, se a deliberação for restrita ao debate sobre princípios de justiça, apenas muito raramente deliberamos nas sociedades reais. A comunicaçáo pública em uma ordem política democrática não é apenas uma forma de deliberação entre

2 Como evidenciam Elstub, Ercan e Mendonça (2016) essa ampliação no conceito de comunicação prevalece desde ao menos a segunda geração dos estudos deliberativos, que se origina a partir de críticas ao caráter exclusivista de "deliberação racional" suposto nas primeiras elaborações teóricas na perspectiva deliberativista. No artigo de Elstub, Ercan e Mendonça (2016), há uma exposição exaustiva sobre a "estrutura geracional” da vertente deliberativa.

3 No original: studying deliberation as a mass phenomenon means talking about phenomena, that is, generalizing about multiple, plural, and overlapping forms of political talk over time and place.

4 Gostaria, em primeiro lugar, de evitar a associação exclusiva entre deliberação pública e uma forma de argumentação crítica, que traz consigo, via de regra, uma concepção impregnada de viés cultural, associada a contextos institucionais particulares, tais como o debate científico, os parlamentos modernos, os tribunais e os salões e cafés que se desenvolveram nas sociedades burguesas europeias do século XVIII. Esses fóruns, como sabemos, pressupõem uma forma de expressão determinada de antemão, tanto institucional quanto normativamente. 
sujeitos que compartilham de antemão certos entendimentos básicos. Ela é frequentemente uma luta entre os membros de uma sociedade para ter os seus interesses, suas experiências e opinióes reconhecidos pelos demais, uma disputa para persuadir os que fazem parte de uma mesma associação da justiça das reivindicaçóes de cada um. A defesa de interesses no espaço público constitui parte do que a própria teoria deliberativa denomina afirmação de si. Faz sentido, portanto, sugerir que a deliberação não deve ser apenas um confronto racional de argumentos críticos para solucionar um problema coletivo. Ela não deve excluir a representação de interesses pessoais, tampouco estar restrita a contextos institucionais formais de diálogo face a face. A comunicação, no sentido a ela atribuído neste trabalho, embora não seja meramente uma "conversa", não se limita aos espaços institucionalizados nem confere exclusividade à argumentação racional (YOUNG, 2001) .

Formas e conteúdos distintos de expressão circulam nos vários níveis da comunicação pública, desde os debates estruturados de acordo com normas institucionais até a conversação cívica que mantemos no dia a dia com as pessoas mais próximas de nós (SEARING et al., 2007). Embora as interaçôes cotidianas sejam a fonte fundamental da elaboração das atitudes políticas dos cidadáos, estamos, via de regra, expostos a uma diversidade de conteúdos discursivos que contribuem para a formulação de razóes a favor ou contra determinado curso de ação pública. As interaçóes discursivas sobre temas moralmente relevantes, como o ideal de boa vida e a interpretação das necessidades, surgem no mundo da vida e reverberam posteriormente na esfera pública. Nas diversas arenas do espaço público, as questôes que emergem no mundo da vida são tematizadas e os pontos de vista e as opinióes podem se transformar em argumentos razoáveis, capazes de emergir como justificação às decisôes políticas. A esfera pública é, a qualquer tempo, a morada de uma constelação de discursos, compreendidos em termos de "um modo compartilhado de compreender o mundo incrustado na linguagem” (DRYZEK, 2004, p. 49).

5 Iris Young denomina essa teoria ampliada de "democracia comunicativa" no intuito de "indicar a atribuição igual de privilégios a qualquer forma de interação comunicativa [...] Enquanto a argumentação é elemento necessário num esforço para discutir e convencer outros sobre questões políticas, pode ser expressada de diversas maneiras, entremeada de, ou paralela a, outras formas de comunicação" (200I, p. 373-374). 
Sem fazer uma afirmação forte sobre os resultados e os valores promovidos pela discussão pública, é possível estabelecer que ela é um fato da vida política democrática. A ação política depende, antes de tudo, do conhecimento que os agentes possuem sobre o mundo social em que estão inseridos. Ela consiste, ao mesmo tempo, em um esforço para produzir e impor representaçóes que sejam capazes de intervir sobre o mundo social e as representaçóes dos agentes a respeito dele. A linguagem tem, portanto, um poder constituinte e estruturante, sendo capaz de modificar a realidade social ao transformar a representação que os agentes têm a respeito dela e dos próprios sujeitos (BOURDIEU, 2008).

Partindo de um esquema proposto por Christiano (1997) - ainda que não siga à risca sua forma de classificação -, vou tomar três concepçóes ideais sobre o lugar da comunicação na democracia, procurando identificar cada uma delas com uma concepção específica sobre os critérios necessários à legitimidade da autoridade política. São elas: (1) a tese da contribuição, que afirma que a discussão pública pode figurar tão somente como uma contribuição para a legitimidade política, cujo critério central seriam os procedimentos formais de formaçáo da vontade democrática; (2) a tese da exclusividade, que afirma que os valores constituídos por meio da comunicação pública são a condição por excelência de uma sociedade democrática, a razão de ser da legitimidade das normas que regulam a conduta dos membros da associação política; e, por fim, (3) a tese da necessidade, cujo argumento central é o de que a deliberação é uma condição necessária à democracia, ou que uma sociedade que toma decisôes sem a deliberação pública é um arranjo indesejável, embora ela não seja suficiente, em si mesma, para tornar justificáveis as decisóes coletivas e seus efeitos $(\mathrm{CH}$ RISTIANO, 1997, p. 246) ${ }^{6}$.

6 Não ignoro os inconvenientes de reunir, em categorias amplas, perspectivas teóricas que em tantos e variados aspectos se opõem umas às outras. Acredito, porém, ser possível mobilizar os autores agrupados nas seções abaixo a partir da relação que estabelecem entre o discurso público e a legitimidade das decisões vinculantes que tomamos em associações democráticas. 


\section{A tese da contribuição}

For in the end, democracy is but a framework within which somewhat equal, somewhat effective, and somewhat free people can struggle peacefully to improve the world according to their different visions, values, and interests. (PRZEWORSKI, 2010, p. 18).

É possível identificar, na teoria democrática, diversas interpretações minimalistas sobre o papel da comunicação pública para a justificação das decisões vinculantes. Parece tarefa ingrata tentar incorporá-las em um mesmo quadro analítico. Contudo, ainda que variem na intensidade de seu minimalismo, não creio ser impróprio encontrar um terreno comum que nos permita compreender a visão de tal literatura sobre a contribuição do debate público para a legitimidade de um arranjo democrático ${ }^{7}$. De modo geral, os autores que se filiam a essa perspectiva sustentam que a discussão pública é (em maior ou menor grau) secundária, dispensável, infactível ou mesmo perniciosa nas sociedades contemporâneas.

Partindo de um pressuposto basicamente aceito na teoria política - o de que o regime democrático se fundamenta na indeterminação sobre os fins últimos da vida em comum -, teóricos minimalistas sustentam que o que torna uma decisão aceitável é o fato de que o arranjo por meio do qual ela emerge oferece igual consideração pelos interesses de cada pessoa submetida à sua autoridade (DAHL, 1989). Desse ponto de vista, a democracia se configura como um processo competitivo no qual cidadáos e grupos de interesses lançam programas políticos e se esforçam para conseguir o apoio do maior número de pessoas. Os atores políticos e sociais se comportam estrategicamente e administram as suas açóes e coalizóes de acordo com a sua própria percepção da dinâmica de preferências na sociedade. Se assumimos que este processo é aberto e justo, os resultados deverão refletir, em todos os níveis, a agregaçáo mais amplamente sustentada de preferências em uma sociedade (DOWNS, 1999). De acordo com essa concepção, portanto, as decisóes políticas - e a própria sobrevivência do regime democrático - são o resultado contingente da competição política.

7 Refiro-me aqui, grosso modo, ao elitismo democrático, representado por Schumpeter; à teoria econômica da democracia, desenvolvida por Downs; no minimalismo de Przeworski; e, em certo sentido, ao pluralismo dahlsiano, este que, embora incorpore elementos normativos, ainda parece identificar no arranjo decisório a justificação da autoridade política. 
As teses da contribuição não têm como intuito central estabelecer quais procedimentos específicos poderiam produzir resultados mais justos. De toda maneira, oferecem uma série de elementos necessários e condiçôes suficientes à construção de um arranjo político em que não haja uma desigualdade significativa na consideração dos interesses dos cidadáos. Do ponto de vista institucional, a igual consideração pelos interesses de todos depende de mecanismos em que, por definição, as escolhas de todos tenham igual valor. Ora, nada mais natural do que localizar o núcleo do empreendimento democrático naquele instrumento que, dentre os mecanismos democráticos ora conhecidos, oferece peso idêntico à participação de cada um, isto é, o voto.

Nas concepçóes minimalistas, a legitimidade deriva do direito ao voto em eleiçốes livres, igualitárias e secretas, e, em alguma medida, na teoria pluralista, da atuação de grupos de interesses em barganhas junto e no interior do sistema político. A plausibilidade dessa ideia se assenta em uma espécie de "subjetivismo ético". Esta forma de subjetivismo, por um lado, seculariza o entendimento sobre a igualdade humana fundamental, e, por outro, substitui a origem transcendental de comandos obrigatórios por uma validade imanente; ou seja, a validade das normas se sustenta na vontade dos sujeitos determinada a partir da agregaçáo de votos e da estabilidade política até o novo movimento de reunião das vontades políticas (SCHUMPETER, 1961; PRZEWORSKI, 2010).

Para essa perspectiva as convicçóes, uma vez consolidadas, não são racionalmente justificadas; mas, antes, expressam uma decisão que, naquele momento, se torna dominante. Assim, a aceitação das decisóes majoritárias não se fundamenta em apelos ao bem comum, considerado como uma ficção inscrita no "museu de ideias do século XVIII" (PRZEWORSKI, 1999, p. 12). O processo argumentativo tem função meramente retórica e seus efeitos são exclusivamente perlocucionários. Em outras palavras, os termos do debate político devem ser entendidos em sua função de promover a aquiescência de cidadãos, de resto pouco atentos ao que não lhes parece exercer influência mais direta sobre a realização dos seus interesses - isto é, o discurso político tem função "sociopsicológica", não cognitiva. (HABERMAS, 1989, p. 292-293). 
Conforme observa Przeworski (1999, p. 14-15), o que autoriza a coerção é o voto, ou o fato de que todos têm o direito a votar e o voto de todos tem peso igual, não as razóes que estão por trás dele. O sufrágio universal, na ausência de coerção aparente, é o que impóe a todos a obrigação de respeitar os resultados de uma votação e aquiescer com as decisóes coletivas. A democracia persiste porque as pessoas em geral se sentem racionalmente convencidas a obedecer aos resultados de um processo de decisão do qual participaram voluntariamente. Embora o voto náo expresse uma vontade coletiva singular, ele é capaz de assegurar que as decisóes coletivas, mesmo na ausência de um processo comunicativo perene a julgá-las, sejam aceitas como procedimentalmente corretas.

Uma forma de interpretar o controle dos cidadãos sobre os seus representantes afirma que o voto seria um mecanismo de controle retrospectivo, na medida em que os primeiros sejam capazes de discernir se, e em que grau, estes últimos agiram de acordo com o seu melhor interesse. No entanto, se os eleitores não estão adequadamente informados, o voto retrospectivo não poderá ser um instrumento eficaz de accountability, por razóes óbvias (SARTORI, 1994)․․ O sufrágio envolve, necessariamente, uma experiência prévia de formação das opinióes; este é o momento, por excelência, da comunicação no processo democrático. Enquanto o direito de escolher os representantes seria uma "garantia mecânica" da democracia política, a existência de condiçóes adequadas para a formação de opinióes assegura que o voto promova a responsividade (SARTORI, 1994, p. 37-38).

A relevância da comunicação política repousa, nesse aspecto, em sua capacidade de oferecer informaçóes adequadas para que os cidadãos formem preferências autônomas e se tornem julgadores mais preparados para exercer o direito à escolha de elites governantes. O público forma uma audiência mais ou menos atenta (MANIN, 1995), que procura compreender o processo de barganha envolvendo os grupos de interesse a fim de fazer escolhas de acordo com seu melhor interesse. A presença ou a ausência de

8 Por certo, o processo é mais complexo do que poderia ser exposto neste espaço. Essa forma de controle exige uma capacidade de reconstruir toda a cadeia causal, por vezes longa, que liga atores, decisões, políticas, efeitos etc. Adiante menciono outras maneiras, mais complexas, por meio das quais o processo poderia ocorrer. 
uma discussão pública que contribua para a construção de preferências autônomas não é, em si, fundamental à legitimidade da ordem política; i.e., a opinião pública, ainda que moldada de maneira livre de forças arbitrárias, não autoriza o governo a exercer o poder. $\mathrm{O}$ resultado do processo eleitoral, sob o princípio majoritário, configura o equilíbrio contingente que resulta dos ajustamentos espontâneos e automáticos próprios da operação dos mecanismos que asseguram a competição política aberta. A democracia, assim, prescinde da referência a normas, e a sua legitimidade é, também, dependente de contingências que podem a qualquer momento se desfazer (PRZEWORSKI, 1999, p. 15-16).

Os pressupostos expostos acima podem dar forma a diversas interpretaçóes sobre a facticidade do processo democrático. Como veremos a seguir, quanto mais elementos forem inseridos nesse quadro, tanto mais complexa se torna a concepção de seus resultados. Em alguns casos, a comunicação pública ganha mais proeminência; em outros tantos, restringe-se ao debate entre as elites e pode tornar-se, até mesmo, nociva aos interesses dos cidadãos. A forma mais comum de se considerar a organização democrática nas teses da contribuição afirma que os cidadãos têm preferências acerca de políticas públicas e estas preferências guiam a ação de lideranças políticas e governos. Os cidadãos escolhem, para lhes representar, aqueles candidatos que lhes parecem mais afeitos a implementar as políticas que eles, cidadãos, preferem. Os governantes, ciosos de se (re)eleger, fazem precisamente o que aqueles a quem representam desejam, como demonstra o seguinte esquema:

Preferências dos cidadãos $\rightarrow$ Propostas dos políticos $\rightarrow$ Políticas governamentais. ${ }^{9}$

É óbvio que essa visão ultrassimplificada do voto como um controle prospectivo não leva em consideração outros elementos intermitentes que atuam na dinâmica política e que podem distorcer essa estrutura. Dentre eles, não pode deixar de figurar a formação das opinióes dos cidadãos, que, como nos diz Sartori (1994), dependem sobremaneira da estrutura

9 Esta e as demais representações do esquema de formação de opiniões encontram-se em Stokes (1998, p. 125). 
comunicativa e da difusão de informações. Além disso, a implementação de programas de governo depende da distribuição das preferências entre as elites (MANIN, 1995; STOKES, 1998, p. 124).

Outra visão comum entende as preferências como resultado de um processo comunicativo que se dá ao nível das elites. A comunicaçáo, nesse modelo, não se configura de modo geral como algo que se dá de baixo para cima, dos cidadãos para seus representantes. Antes, ela se estrutura como um processo no qual as elites tendem a moldar ou influenciar as crenças dos cidadáos e as suas preferências quanto a temas de interesse público, mediante a opção por determinados enquadramentos ou por meio de forte exposição à comunicação política difundida em cascata (STOKES, 1998, p. 125).

Debate entre a elite $\rightarrow$ Opinião Pública $\rightarrow$ Políticas governamentais.

Para Kinder e Sears (1985), o que importa aos representantes é ter o suporte da opiniáo pública - entre outros motivos, o mais importante sendo o de que haverá, em um futuro pré-determinado, nova rodada de competição pelo poder. Entretanto, desfrutar do apoio da opinião pública não significa necessariamente responder às preferências autonomamente formadas dos cidadáos; significa, em vez disso, enquadrar informaçóes de forma adequada. Tais informaçóes interagem com os valores e as predisposições que são construídos mediante a socialização e as experiências pessoais, estando, portanto, menos sujeitas à influência das elites. De acordo com essa perspectiva,

O papel proeminente que estudiosos da opinião pública conferem à comunicação pública de presidentes, partidos, legisladores, experts, pessoas anônimas, pesquisas de opinião e os meios noticiosos na determinação da forma como os cidadãos pensam sobre a política deveria nos levar a duvidar da visão de que as preferências dos cidadãos são exógenas à comunicação política. Nesse sentido, a deliberação, longe de ser um complemento, talvez um complemento desejável, ao processo democrático, é uma parte inextricável deste processo, para o bem ou para o mal. (STOKES, 1998, p. 126-127, tradução livre). ${ }^{10}$

10 No original: The prominent role that scholars of public opinion assign to the public communications of presidents, parties, legislators, experts, anonymous others, polls, and the news media in determining how citizens think about politics should lead us to doubt the view of citizen preferences as exogenous to political communi- 
Seria possível incluir, ainda, um novo elemento nesse quadro, de modo a sugerir a direção em que se dá a formação de preferências e a sua entrada na construção da vontade política. Outra forma de influência sobre a discussão pública provém de atores privados autointeressados, que intervêm sobre o debate público no intuito de convencer os cidadáos de determinadas "crenças causais" (PRZEWORSKI, 1998), esperando que este público pressione os seus representantes a tomar decisóes baseadas em tais crenças. Nesse sentido, segundo Stokes (1998, p. 128):

Interesses especiais se expressam contra a política $\mathrm{A} \rightarrow$ Cidadãos se voltam contra a política $\mathrm{A} \rightarrow$ Política A rejeitada.

Esta hipótese pode ainda ser expressa de uma maneira diversa, a saber: os lobbies, em vez de influenciarem as opiniốes dos cidadãos, podem agir de modo a influenciar a percepção dos legisladores acerca da preferência dos cidadãos. O Senador Paul Douglas sustenta que este foi o caso na derrubada do fundo para a saúde pública nos EUA no governo Truman. Um processo semelhante, tratando da mesma questão, se deu durante o governo Clinton, em 1992, quando da discussão do programa público de saúde que, de início, desfrutava de amplo apoio do eleitorado (PRZEWORSKI, 1998; STOKES, 1998, p. 129-130). Nesse caso, segundo Stokes (1998, p. 130 ), o processo teria se configurado da seguinte forma:

Interesses especiais se expressam contra a política $\mathrm{A} \rightarrow$ Representantes compreendem equivocadamente (ou não) que o público está contra a política $\mathrm{A} \rightarrow$ Política A rejeitada.

Em uma variante dessa sequência, a transformação das opiniôes públicas pode ser o resultado combinado de uma interpretação equivocada das preferências dos cidadáos, seguida pelo debate entre as elites, que acaba influindo sobre o posicionamento do público. Costuma-se estimar que os formuladores de políticas públicas tendem a se valer das pesquisas de opinião náo para conhecer as preferências dos cidadãos e adaptar as políticas a essas preferências, mas para formular uma estratégia no sentido de convencer a opinião pública de suas próprias preferências políticas e 
posições partidárias. Portanto, “[...] a percepção equivocada da mudança das preferências do público foi o resultado político relevante da deliberação" (STOKES, 1998, p. 129-30)". Para Stokes (1998, p. 132), esse modelo mais complexo poderia ser expresso da seguinte maneira:

Governo propóe $A \rightarrow$ Oposição e cidadãos aquiescem $\rightarrow$ Interesses especiais se manifestam $\rightarrow$ Imprensa reporta oposição da opinião pública a $\mathrm{A} \rightarrow$ Oposição acredita na imprensa e argumenta contra a política $\mathrm{A} \rightarrow$ Cidadãos se opóem à política $\mathrm{A} \rightarrow$ Política $\mathrm{A}$ rejeitada.

Seja qual for a interpretação sobre o processo de formação da opinião pública e da vontade democrática, resta claro que os candidatos, os partidos, os financiadores de campanha e outros grupos de interesses se esforçam para influenciar as crenças dos cidadáos a respeito, não tanto das preferências, mas sobre a relação entre os meios e os fins das políticas públicas que defendem. Tais crenças, por serem endógenas ao processo político, são afetadas pela desigualdade de recursos informacionais e cognitivos. $\mathrm{O}$ mesmo pode ser dito a respeito da desigualdade de recursos no processo discursivo, pois as consequências da ampliação do debate público em um contexto marcado por vastas e variadas desigualdades podem ser altamente indesejáveis do ponto de vista dos interesses dos cidadãos (STOKES, 1998, p. 147).

A exposição acima nos permite ver, com clareza maior, uma objeção adicional à associação da legitimidade política aos processos comunicativos. O que os modelos de formação da vontade democrática apresentados evidenciam é que, em algumas circunstâncias, a discussão pública pode ser perniciosa, porquanto "manipulada" para favorecer interesses particulares. Partindo dessa percepção, o princípio da igual consideração pelo interesse de todos, que justifica e se materializa nas regras da competição política, afasta a legitimidade da ordem democrática dos processos discursivos.

Uma das razóes pelas quais Mill (2000) defendeu de maneira tão enfática a importância da discussão para a vida pública tem a ver justamente com a possibilidade que esta cria para que dissidentes exponham conven-

I I No original: misperception of changed public preferences was the politically relevant outcome of deliberation. 
çôes e preconceitos. Entretanto, a dinâmica argumentativa das democracias contemporâneas se afasta cada vez mais do ideal de discurso público projetado por Mill, especialmente devido ao grau em que este processo está maculado pela influência do poder econômico (SHAPIRO, 2003, p. 225226). Como sugere Przeworski, num contexto de desigualdade profunda de recursos, “a deliberação pode levar à 'dominação ideológica”" (1998, p. 140) ${ }^{12}$. A comunicação pública, portanto, pode induzir as pessoas a sustentarem crenças que são, a um só tempo, pouco acuradas e mais favoráveis aos interesses dos que dispóem de recursos que lhes permitam ocupar a posiçãa de líderes de opiniāo.

A perspectiva apresentada nesta seção sustenta, assim, que os processos comunicativos estáo inevitavelmente envoltos em um mar de contingências, em especial na medida em que são levados a cabo em sociedades caracterizadas pela persistência de desigualdades de recursos em diversos níveis. Nesse sentido, ainda que a etapa de formação das opinióes seja relevante para as escolhas que fazemos quando convocados a participar das decisóes políticas, diretamente ou por meio da escolha de representantes, a legitimidade do arranjo político náo pode depender dos processos comunicativos, na medida em que estes podem ser, e constantemente o são, enviesados e parciais.

Para as teses contribuicionistas, o regime político democrático seria uma espécie de resposta tentativa a um contexto em que permanece a indeterminação em relação aos fundamentos últimos da vida em sociedade. $\mathrm{Na}$ medida em que não podemos encontrar critérios mais substantivos a partir dos quais sustentar a autoridade política, as teses da contribuição apostam as suas fichas nos procedimentos agregativos que, como nos diz Przeworski (1999), asseguram a obediência sem recorrer ao subterfúgio da violência.

A democracia, dessa perspectiva, é uma forma de ser governado, não o contrário. Reconhecendo de saída que a sociedade é marcada pelo conflito de valores e interesses presumivelmente irreconciliáveis, o processo eleitoral autoriza a coerção na medida em que reflete o equilíbrio de forças e a distribuição de preferências no eleitorado. Eis, segundo Przeworski, o

12 No original: deliberation may lead to 'ideological domination'. 
milagre da democracia: as forças políticas em conflito acatam o resultado das urnas, o governo póe em risco seu poder ao se submeter ao processo eleitoral; a oposição, por sua vez, recolhe as "armas" e aguarda a próxima rodada de disputa. Ao final, os conflitos são regulados e, portanto, limitados. Nesse sentido, os votos são como "pedras de papel”, na metáfora usada por Engels (PRZEWORSKI, 1999, p. 15-16).

\section{A tese da exclusividade}

Democracy is not an alternative to other principles of associated life. It is the idea of community life itself... [It is] a name for a life of free and enriching communion. (DEWEY apud BARBER, 1984, p. 117).

A tese a ser exposta nesta seção identifica, nas interações comunicativas, o núcleo da justificação da autoridade coletiva da sociedade. Embora haja variaçóes no que se refere a certos requisitos normativos e à materialização institucional da democracia, a razão de ser do regime democrático, para os autores que se filiam a essa tradição, é o processo associado à autorrealização de cidadãos inseridos em uma comunidade de iguais. As controvérsias sobre o lugar da comunicação na justificação da autoridade política se referem ao seu papel na cooperação política. Enquanto a literatura associada ao republicanismo cívico ${ }^{13}$ sustenta que a comunicação depende, para ocorrer a contento, da presença de valores éticos que a subjazem, a perspectiva ligada à ideia de "democracia forte" 14 entende que a comunicação cria e dá forma aos pressupostos da cooperaçáo.

A concepção da exclusividade - que se alimenta, em boa medida, das teses associadas ao republicanismo cívico e das teorias participativas da democracia - não aceita a restrição da política ao processo competitivo (como o modelo contribucionista), pois considera a política como o processo de constituição da própria comunidade e, em alguns casos, como a realização de um ideal de boa vida. Há duas visóes que subjazem a essa perspectiva. De um lado, o foco recai sobre a identificação prévia dos indivíduos com a ética comunitária, que seria atualizada por meio da participação dos

13 Refiro-me aqui a autores como Michael Sandel e Charles Taylor, cujos argumentos vou examinar a seguir.

14 As referências centrais nessa posição são as obras de Carole Pateman e Benjamin Barber. 
cidadãos no discurso público; de outro, há uma ênfase sobre o compromisso que deve ser obtido por meio do engajamento dos cidadãos no processo de autodeterminação coletiva, que teria um impacto sobre as virtudes cívicas dos que dele tomam parte.

$\mathrm{Na}$ posição que se aproxima do republicanismo cívico, a formação da vontade democrática assume a forma de um autoentendimento ético-político, no qual a ordem democrática se sustenta no consenso de fundo culturalmente estabelecido e compartilhado pelos cidadãos. A comunidade política seria uma comunidade ética pré-política e o bem comum se converte em uma substância previamente existente, parte da essência de uma comunidade que deve ser reafirmada por meio da comunicação livre entre iguais (SANDEL, 1998). Já em outra visão, menos aferrada à necessidade de um consenso cultural de fundo, a democracia se assenta na ideia de uma comunidade autogovernante de cidadãos, que são unidos menos por valores homogêneos do que por sua capacidade de compartilhar objetivos e agir em um concerto sustentado em suas virtudes cívicas e seu senso de justiça (BARBER, 1984).

A primeira posição remete a um entendimento de raiz aristotélica, que enxerga a pólis como um regime político dotado de uma finalidade específica, a saber, a realização do bem comum. Este objetivo lhe dá forma e constitui a comunidade como um sistema no qual as instituições expressam um modo de vida particular. A eticidade de um Estado não se constitui da soma de suas partes. Ela é, antes, a representação de avaliaçóes substantivas que dão origem à identidade entre os espíritos subjetivo e objetivo da sociedade (FORST, 2010, p. 129 ss).

Rousseau (2006) pode ser considerado o teórico fundamental para a segunda perspectiva. Nessa visão, não se pressupõe uma unidade ética substantiva dos cidadáos; tal unidade seria o resultado mesmo do processo de participação política por meio do qual os cidadãos realizam a sua liberdade e produzem a vontade geral. Cidadáos politicamente virtuosos são capazes de concertar a sua razáo, tal como em um moteto, emprestando objetividade à soberania popular mediante a expressão da vontade geral. $\mathrm{O}$ elemento da soberania popular direta, nesse contexto, tem um efeito sociopsicológico sobre os cidadãos, garantindo uma inter-relação entre o 
processo democrático e o fomento das capacidades esperadas dos membros da sociedade que exercem a sua autonomia política. $\mathrm{O}$ autor genebrino destaca o processo de aprendizado permanente que é inerente ao exercício da autodeterminaçáo coletiva. Os cidadãos são levados a considerar temas e perspectivas bem mais abrangentes do que os seus interesses privados lhes poderiam oferecer. Esse mecanismo contribui para que tomem decisóes recorrendo a um senso de justiça (PATEMAN, 1992, p. 37-39).

Vejamos, a seguir, mais detidamente como as duas vertentes se apresentam.

No núcleo da versão mais forte da ética comunitária, encontra-se um movimento que vai de encontro ao privatismo de uma sociedade despolitizada. Segundo essa primeira vertente, uma associação política deve ser uma comunidade ética culturalmente integrada, pois tal integração sustenta a soberania e a solidariedade que possibilitam o exercício da autodeterminação coletiva. Seria impossível, segundo essa perspectiva, a formulação de uma ideia coerente da moral sem uma concepção abrangente do bem como télos, ou seja, não seria concebível uma comunidade política na ausência de um ideal compartilhado do bem viver. Rejeita-se, assim, não apenas a moral universalista desligada do contexto social, cultural e político, mas, também, a própria possibilidade de se fundamentar a comunidade política em um abstrato pluralismo de valores.

Uma comunidade política "autêntica” deve apresentar uma forma de práxis comunitária ancorada na tradição moral na qual os indivíduos podem se reencontrar. A narrativa da vida individual deve ser parte de uma narrativa de ordem superior. O télos eticamente desejável da vida deriva dessa trindade de práxis, tradição e biografia subjetiva: desejável é um "valor interno" às práticas sociais. (FORST, 2010, p. 132).

Considera-se, nesse aspecto, que a relação de pertencimento comunitário é inevitavelmente constitutiva das identidades privadas. Bellah (1991), em uma versão da doutrina do interesse bem compreendido ${ }^{15}$, sustenta que, mesmo em uma sociedade que conviva com o pluralismo de valores razoáveis, faz-se necessário o reconhecimento de um "pluralismo

15 Ver Tocqueville (2004), Livro II, segunda parte. 
aprofundado" a que os cidadãos possam recorrer no intuito de formular o bem comum como parte de seu próprio bem particular.

A identificação dos cidadãos com a comunidade, que em alguns casos se traduziu como a virtude do patriotismo, se dá na medida em que a coletividade incorpora certos valores necessários à sua autocompreensão, bem como normas com as quais os cidadãos são capazes de se identificar em “avaliaçóes fortes". Haveria dois critérios essenciais para uma identificação forte como condição necessária à autodeterminação pública. $\mathrm{O}$ primeiro deles seria o reconhecimento das formas participativas da política para a determinação do próprio sentido comunitário de integração. $\mathrm{O}$ segundo, por sua vez, seria um senso forte de comunalidade que se sustenta e se mantém através da participação (TAYLOR, 2000) ${ }^{16}$.

A participação no processo discursivo, nesse sentido, não cria o propósito comum; antes, a sua realização pressupóe a existência de tal consenso, que se reforça e se reproduz por meio da discussão pública. Contra o que considera uma abstração típica do liberalismo clássico, essa literatura destaca o enraizamento das concepções de bem nas autocompreensões e nas tradiçóes constitutivas da comunidade autogovernante. Esta, com seus valores e práticas amadurecidos historicamente, dá origem a um horizonte valorativo que é a própria urdidura das identidades de seus membros. Assim, a integração política, a soberania, se quisermos, se configura como a afirmação de certa unidade que se ampara nos valores ético-culturais compartilhados intersubjetivamente mediante uma comunicação amparada em valores comuns (FORST, 2010, p. 114-117).

Mesmo a igualdade política só faz sentido quando remete à pertença de todos a um mundo compartilhado intersubjetivamente. Por igualdade, não se entende que todos sejam iguais perante a lei, tampouco que a lei seja igual para todos; trata-se de algo mais profundo: de uma igualdade compreendida como a concessão dos mesmos direitos e condiçóes efetivas de realizar as atividades tipicamente humanas, i.e., as açóes políticas - e, por desfrutarem de tais condiçóes em um contexto comunitário de

I6 O exemplo sugerido por Taylor (2000, p. 220) seria o Canadá. Todavia, o autor encontra apenas a primeira dessas condições no país. A segunda, uma identidade nacional eticamente constituída, não se faz presente no país, que convive com um pluralismo de valores éticos, etnias e preferências. 
normas compartilhadas - os cidadãos exercem, de fato, o direito à liberdade (ARENDT, 2007).

A segunda vertente, dentro da tese exclusivista, toma a política como uma "forma de viver" (em oposição a uma "forma de vida"). O fazer político aparece como um empreendimento por meio do qual os cidadáos, com interesses distintos, mas possivelmente sobreponíveis, podem conviver entre si sem que nenhum deles exerça domínio sobre os demais. A competição de interesses privados e o conflito que eventualmente surge dessa competição não têm nessa ideia forte de democracia uma forma de resolução. Supóe-se haver, todavia, uma maneira de criar uma linguagem pública que seja capaz de reformular a defesa desses interesses em termos suscetíveis de serem acomodados publicamente (BARBER, 1984, p. 119).

É possível entender o mundo político como circunscrito por condiçôes que tornam obrigatória a ação pública, e por extensão uma escolha pública razoável, em um contexto no qual o conflito não pode ser resolvido em campo privado ou independente do julgamento da comunidade autogovernante. Dessa forma, é preciso agir e tomar decisóes que afetam todos em uma coletividade, ainda que haja discordância tanto em relação aos fins quanto em relação aos meios de fazê-lo. Segundo Barber, a possibilidade de se chegar a acordos políticos remete à própria experiência política: "[...] a política é o que os homens fazem quando a metafísica falha; não é a metafísica reificada como uma Constituição" (1984, p. 128-129) ${ }^{17}$.

Segundo essa ideia, a política é realizada pelos cidadãos e não para eles; a sua principal virtude é a atividade, sendo a comunicação, a decisão e o trabalho comuns sua marca distintiva. Confere-se centralidade, assim, à agência e à responsabilização, pois se lhes reconhece como elementos centrais à ação dos cidadãos em face dos conflitos inerentes às sociedades humanas - rejeitando-se a conclusão de que o conflito é intratável e somente pode ser passível de tolerância ou adjudicação. A forma como a política é aqui pensada confere à participação dos cidadãos, à deliberação e à educaçáo cívica a tarefa de fomentar meios através dos quais o conflito possa ser

17 No original: Politics is what men do when metaphysics fails; it is not metaphysics reified as a constitution. 
reelaborado como cooperação. Se a política nessa teoria se inicia no conflito, ela não termina com uma mera acomodação de posiçôes concorrentes, mas propóe uma ação transformadora (BARBER, 1984, p. 134-135).

A legitimidade de um valor é função de seu caráter público, de como é refinado e modificado quando confrontado com o público e as normas públicas previamente definidas no processo político. Essa forma de autoridade emerge, portanto, da transformação que ocorre na comunicação à qual estão sujeitos estes julgamentos. Ao contrário da barganha, em que se define entre opçóes previamente determinadas, na política de transformação os atores políticos são levados a modificar e ampliar as suas opções ao entrar em contato com novas opinióes, preferências, interesses e pontos de vista (BARBER, 1984, p. 134-135).

Essa forma de "democracia forte" (BARBER, 1984) exige, de um lado, uma cidadania ativa, que participe tanto ao nível local quanto nacional, que se engaje na discussão pública e nas decisões - uma forma de autogoverno que dispensa, em boa medida, as instâncias tradicionais de mediação. De outro, requer a constituição de instâncias deliberativas que tornem o sistema político e social uma forma de "associação de associaçôes", nas quais a comunicação seja não apenas um fim, um objetivo, mas também o meio através do qual seria possível construir consensos legítimos. Assim, a legitimidade das leis não pode ser desvinculada do processo de sua gênese: há uma conexão interna entre as práticas de autodeterminação pública e o império da lei, entre procedimento e substância.

O autogoverno democrático não tem valor apenas instrumental, como método para a escolha de governos, mas é parte constitutiva da própria ideia de liberdade. A liberdade pessoal não se restringe ao estabelecimento de uma área livre de interferências, ela consiste em uma forma de agir. Em certo sentido, pode-se afirmar que o resultado da ação comunicativa é a própria política, entendida como a interação entre iguais na esfera pública. Ação e política, segundo Arendt (2007), são, dentre todas as capacidades e potencialidades humanas, as únicas que não poderíamos sequer conceber sem admitir a existência da liberdade. Para ela, "[a] raison d'être da política é a liberdade, e seu domínio de experiência é a ação" (ARENDT, 2007, p. 192). 
Os direitos ganham, nesse sentido, um caráter de liberdades positivas, no sentido de Berlin (2002); nestes direitos, destacam-se os direitos de participação e comunicação políticas. Estas últimas garantem aos cidadãos o status de autores políticos responsáveis pela constituição e reprodução da comunidade. $\mathrm{O}$ poder político é gerado na prática da autodeterminação dos cidadãos e se legitima pela institucionalização e pela realização das liberdades públicas. A existência do Estado e das instituiçôes políticas justifica-se como garantia de um processo comunicativo inclusivo de formação das vontades políticas. Mas os encargos relativos à distribuição dos benefícios da cooperação, assim como a constituição da própria comunidade, estão assentados na agência política dos próprios cidadãos. Os procedimentos de autolegislação e construção comunitária são genuinamente independentes de normas externas, verdades pré-políticas e direitos naturais (HABERMAS, 1995).

A autonomia do processo político garante uma equalização nos pontos de partida e associa a legitimidade ao que ocorre com as convicçôes e os valores no curso do processo de discussão e ação política. As instituições formais emergem como expressão das reivindicaçôes de uma "democracia forte”, em que a discussão, o julgamento e os encontros públicos aparecem como alternativa à representação, ao voto e ao governo dos burocratas e especialistas (BARBER, 1984, p. 262-263). Os componentes básicos do projeto são voltados para a discussão pública, o processo de decisão e a ação criadora da política, no sentido material do termo - à comunicaçáo, nesse aspecto, confere-se um valor intrínseco, tornando-se um elemento substantivo na justificação da autoridade política.

\section{A tese da necessidade}

Tomando como referência os rótulos sugeridos por Christiano (1997), chegamos, finalmente, à perspectiva da necessidade, terceira forma de abordagem sobre o papel da comunicação na justificação das decisóes políticas. A tese da necessidade baseia-se, grosso modo, no que se convencionou denominar como a teoria deliberativa da democracia. Desde a sua primeira fundamentação, que remonta ao trabalho do filósofo alemáo, Jürgen 
Habermas ${ }^{18}$, nota-se uma preocupação em lançar luz sobre a capacidade que a dinâmica argumentativa presente (ou latente) nas sociedades contemporâneas teria de gerar decisóes racionais. Os estudos deliberativos se debruçaram sobre uma série de elementos e características da comunicação pública, bem como analisaram múltiplas instâncias deliberativas, procurando entender desde os aspectos teórico-normativos - notadamente em sua primeira geração - até questôes relacionadas à estrutura institucional dos arranjos deliberativos (ELSTUB; ERCAN; MENDONÇA, 2016).

Em sua fase mais recente, que Elstub, Ercan e Mendonça (2016) sugerem tratar-se de uma quarta geração dos estudos deliberativos, a literatura tem voltado a lidar mais diretamente com questôes teórico-normativas ${ }^{19}$, conferindo uma renovada atenção e um olhar inédito sobre ideia de "sistemas deliberativos", presente já na perspectiva habermasiana ${ }^{20}$. A abordagem sistêmica apresenta ao menos três aspectos que nos interessam mais diretamente aqui, quais sejam: (a) um esforço para compreender a deliberação em larga escala, (b) a ideia de uma divisão do trabalho deliberativo entre múltiplas arenas e, por fim, (c) a concepção de critérios distintos para avaliar a deliberação nas diversas instâncias onde ela ocorre, conferindo um papel importante a espaços menos propriamente deliberativos no conjunto mais amplo do sistema (ELSTUB; ERCAN; MENDONÇA, 2016, p. 143-144).

Uma abordagem como essa se afasta da perspectiva baseada nos modelos de democracia, que opunha a democracia competitiva à democracia

I8 Algumas abordagens observam, porém, que já no começo do século XX, teríamos a formulação de uma teoria deliberativa da democracia, nos trabalhos de Dewey, Mead. Ver, por exemplo, Mendonça (2016).

19 Ainda que se possa argumentar que a terceira geração não tenha deixado de lado as questões teóricas, não me parece de todo impróprio afirmar que houve uma ênfase em estudos sobre a praticabilidade da deliberação, de modo que os estudos dirigiram um olhar especial para a pesquisa empírica acerca da qualidade da deliberação e dos elementos que impactam sobre ela, notadamente em espaços mais restritos, como minipúblicos, conselhos, conferências e orçamento participativo.

20 O esforço no sentido de elaborar uma concepção sistêmica da democracia vem sendo levado a cabo por um grupo de teóricos da democracia, a maioria norte-americanos. A coletânea editada por Parkinson e Mansbridge, em 2012, é o resultado mais acabado da conferência Democracy and the Deliberative Society, que fora realizada, em 2009, na University of York. A ideia dos autores que contribuíram para o trabalho é elaborar uma concepção da democracia deliberativa, baseada nas ideias formuladas por Habermas, que concorra para uma compreensão de como a deliberação pública perpassa toda a sociedade, e não apenas os fóruns mais restritos, como convencionalmente têm se teorizado a respeito dela. 
diretamente participativa. Para a perspectiva dos sistemas deliberativos, a comunicação pública não substitui a agregação de votos, tampouco a representação pode ser considerada como um second best da participação. Nos "modelos de democracia”, é comum que se defina um mecanismo particular - seja a agregação de preferências, seja o discurso público - como suficiente para garantir a legitimidade da autoridade política ${ }^{21}$. Ao opor a comunicação pública à agregação de votos, as perspectivas holísticas argumentam que estes elementos devem executar as mesmas tarefas em um sistema democrático. A tese da necessidade, por sua vez, tem uma interpretação diversa. Segundo essa perspectiva, é preciso observar o sistema de uma maneira ampla, procurando compreender as funçóes realizadas por cada parte e de que modo podem contribuir para a democratização da sociedade. Nesse sentido, a comunicação pública poderia ser capaz de realizar certas funções, como a formulação das razôes aceitáveis à justificação das decisóes coletivas, enquanto a agregação, ao garantir o mesmo peso ao voto de todos, poderia promover a representação do dissenso, ambos elementos fundamentais para a legitimidade das decisóes coletivas (MANSBRIDGE et al., 2012).

Para compreender o papel da comunicação seria necessário observar o caráter das funçôes realizadas por um sistema político democrático, procurando analisar os mecanismos mais adequados a oferecer uma resposta a eles. Ao considerar a democracia como um "sistema deliberativo", evidencia-se a diferenciação e a integração entre as partes, assim como certa divisão de funçôes entre elas. Essa ideia é, ao mesmo tempo, normativa e sistemática: normativa no sentido de definir normativamente como um sistema democrático deve funcionar; sistemática por supor que determinados procedimentos e resultados são normativamente mais adequados a certas instituições e não a outras (MANSBRIDGE et al., 2012; WARREN, 2012).

As sociedades contemporâneas se reproduzem por meio de uma série de sistemas diferenciados, cada um dos quais com objetivos, mecanismos de coordenação e critérios de sucesso distintos. As universidades, os mercados, os media e as instituiçóes do Estado se organizam e operam em lógicas

21 Como, aliás, fica evidente pela argumentação apresentada nas seções anteriores, em que os modelos contribucionista e exclusivista formulam a sua posição em contraponto uma à outra. 
específicas, que traduzem as interações dentre e entre eles de acordo com seus próprios códigos. Um sistema deliberativo democrático inclui desde interaçóes informais até decisóes vinculantes que ocorrem em âmbito externo ao Estado Nacional, em organismos internacionais e supranacionais, nas arenas societais e corporativas:

Estados liberal-democráticos e constitucionais criam espaços de deliberação em instituições políticas, tais como as legislaturas e as cortes. Eles também possibilitam a deliberação na sociedade ao proteger a liberdade de discurso e de associação. Eles encorajam a deliberação ao subscrever instituições em que a deliberação é, em si mesma, constitutiva, tais como universidades e fundações de pesquisa científica. Mas ainda que Estados realizem um papel central e comumente constitutivo em sistemas deliberativos, nem todas as partes do sistema levam ao Estado. O Estado não é o fim de toda deliberação.(MANSBRIDGE et al., 2012 p. 10) 22.

Os sistemas deliberativos incluem quatro dimensóes principais: (1) as decisóes coletivas vinculantes do Estado (sobre as leis e a sua implementação), (2) atividades ligadas à preparação para tais julgamentos, (3) conversas informais relacionadas a tais decisóes e (4) arenas de discussão formal e informal acerca das decisóes sobre questóes de interesse comum que náo são dirigidas às decisóes coletivamente vinculantes. Uma sociedade democrática, nesse aspecto, "[...] possibilita um enquadramento normativo das consequências causais de uma variedade de dispositivos democráticos" (WARREN, 2012, p. 6) ${ }^{23}$.

Há aqui, portanto, uma compreensão sobre a relação entre democracia e comunicação pública, ou melhor, uma interpretação sobre o papel constitutivo da comunicação na justificação da autoridade, que incorpora este elemento de forma ampla como dispositivo necessário para assegurar, como sugere Cohen (1998), o caráter coletivo das decisóes políticas. De acordo com este entendimento, a legitimidade das decisóes vinculantes

22 No original: Liberal-democratic, constitutional states create spaces of deliberation within political institutions such as legislature and courts. They also enable deliberation within society by protecting free speech and association. They encourage deliberation by underwriting institutions in which deliberation is itself constitutive, such as universities and scientific research establishments. But even though states play a central and often constitutive role in deliberative systems, not all efficacious and important parts in the system lead to the state. The state is not the terminus of all deliberation.

23 No original: enables normative framing of the causal consequences of variety of democratic devices 
depende dos processos comunicativos que ocorrem na sociedade civil, nas instituiçôes do sistema político, nas instâncias deliberativas formais e entre tais arenas. No entanto, a comunicação - sobretudo quando os critérios para a qualidade da deliberação são demasiado exigentes ou quando pressupôem a existência prévia de uma compreensão ética compartilhada pela comunidade - não assegura, por si mesma, a justificação da autoridade política em um sistema democrático.

$\mathrm{Na}$ tese da necessidade, a comunicação pública seria "[...] um modo de formular os planos (de uma associação política), de estabelecer seus objetivos e construir suas decisóes de acordo com o plano traçado" (RAWLS, 2011, p. 212). A deliberação, nesse sentido, ocorre em inúmeros tipos de sistemas sociais, embora não haja, para todos eles, o mesmo tipo de exigência quanto ao arranjo institucional e à qualidade dos argumentos. A discussão pública pode acontecer em enclaves isolados da comunidade de pessoas afetadas pelas decisóes ou, ainda, mais tipicamente, entre uma elite proporcionalmente diminuta, cujos argumentos são predominantemente técnico-legais e não remetem à formação reflexiva de preferências dos cidadáos. Mesmo na presença de instituiçóes formalmente democráticas, outros sistemas de poder pressionam as decisóes em direçóes que se afastam do controle por meio do consenso popular, como o sistema judiciário e a burocracia administrativa (MANSBRIDGE et al., 2012).

A democracia, da forma como a compreende a tese da necessidade, remete a duas ideias. A primeira, mais óbvia, é a de que, em um regime político democrático, as decisóes sobre os rumos da sociedade são coletivas em algum sentido. Assim, uma decisão será devidamente coletiva na medida em que for o resultado de um arranjo institucional que estabeleça condições adequadas para a comunicação pública livre entre iguais (COHEN, 1998, p. 185-186). Condiçóes, estas, que dependem tanto de direitos formais que não estão submetidos ao consenso popular - mesmo aquele gerado "comunicativamente" -, quanto do que Rawls $(2008,2011)$ denominou de "valor equitativo das liberdades políticas"24. Segundo Cohen, esta compreensão sobre a natureza coletiva das decisôes políticas se distingue

24 A democracia, na concepção deliberativa, não é apenas uma forma política. Segundo Cohen (1998, p. I86), a democracia é "uma estrutura de arranjos sociais e institucionais". 
de maneira fundamental das concepçóes que ele denomina "agregativas". Nestas o caráter coletivo das decisões se sustenta no fato de que "[...] emergem de arranjos de escolhas coletivas vinculantes que conferem igual consideração - ou, mais genericamente, são positivamente responsivos - aos interesses de cada pessoa vinculada às decisóes" (COHEN, 1998, p. 186) ${ }^{25}$.

A segunda ideia, associada a esta última, afirma que a democracia se assenta na justificação da autoridade. Os cidadãos tratam uns aos outros como iguais na medida em que se esforçam por oferecer razóes para as decisóes que possam ser mutuamente aceitáveis por todos aqueles que estão submetidos ao poder coletivo da sociedade (COHEN, 1998) ${ }^{26}$. A argumentação pública se apresenta, portanto, como um componente central da justificação política, que exige a conformação de um sistema de arranjos políticos e sociais que liga institucionalmente o exercício do poder político à comunicaçáo pública entre iguais. A comunicaçáo pública aparece, destarte, como um processo por meio do qual os cidadáos, enquanto um corpo coletivo, chegam a alguma forma de compreensão sobre suas metas comuns (ANDERSON, 2009).

A ideia de igualdade política, nessa definição, sustenta que os membros de uma sociedade democrática devem ser substantivamente iguais no sentido de que a distribuição de poder e outros recursos não molde definitivamente as suas chances de contribuir para a argumentação pública, nem represente um papel impositivo na participaçáo de cada um nas decisóes coletivas. Trata-se, portanto, da garantia de um valor equitativo das liberdades comunicativas", pois estas liberdades são os meios institucionais essenciais para a realização das liberdades fundamentais (FRANCISQUINI, 2014). A possibilidade de formação de razóes públicas está condicionada à possibilidade de os cidadãos argumentarem dentro de um sistema comunicativo, ainda que indiretamente e a partir de arenas dispersas ao longo do sistema.

25 Nesse sentido, a agregação de preferências expressas por meio do voto, cujo peso de cada um é igual ao de todos os outros, constitui o mecanismo fundamental através do qual emergem decisões justificáveis porque são propriamente coletivas.

26 Segundo Cohen, "[...] a consideration is an acceptable political reason just in case it has the support of the different comprehensive views that might be endorsed by reasonable citizens" (1998, p. 195). 
Isso envolve, por um lado, a forma de organização da estrutura básica e o quanto as instituiçôes que a compôem exercem duas funçôes: (a) facilitar a livre argumentação oferecendo, por exemplo, condiçôes favoráveis à expressão, à participação e à associação; e (b) amarrar a autorizaçáo para o exercício do poder coercitivo da sociedade à justificação pública, mediante a construção de um arcabouço institucional que favoreça a responsividade e o accountability do poder político, estabelecendo eleiçóes periódicas, transparência das decisóes legislativas, liberdade de expressão e de imprensa, espaços de interação e julgamento públicos. Por outro, exige também a proteção aos valores da tolerância, às liberdades que asseguram o livre exercício da autodeterminação individual e as bases sociais do autorrespeito (RAWLS, 2003, p. 59). Tal proteção implica e se justifica pelo reconhecimento do status de igualdade entre os cidadãos "[...] no que respeita à realização dos julgamentos impositivos finais sobre os assuntos coletivos" (COHEN, 2003, p. 109) $)^{27}$.

Ao considerar o processo argumentativo na esfera pública uma condição necessária - ainda que não suficiente - para conferir legitimidade à autoridade política, essa visão ressalta a importância de processos em que todos os membros de uma associaçáo possam tomar parte, não apenas exercendo influência pelo processo comunicativo mas também assinando petiçóes, tomando parte em protestos, participando de movimentos sociais e de outras associaçóes da sociedade civil e, por que não, votando. Explicita-se, com isso, o vínculo entre as diversas dimensóes da política democrática, que vão desde as açóes expressivas e comunicativas na esfera pública, passam pela barganha política e a negociação de interesses, e chegam até o ato de tomar parte das decisóes coletivas por meio do voto para a escolha de representantes e de políticas públicas ${ }^{28}$.

As decisóes coletivas possuem um aspecto que não se sustenta no discurso, mas que seria ato "puro" e silencioso de vontade, o que não está

27 No original: with respect to making the final authoritative judgments about collective affairs.

28 Parece-me que era este, em boa medida, o argumento de Habermas, em conferência proferida em I99I, quando ele estabelece a teoria do discurso entre os polos do paradigma liberal e republicano, aproveitando deste a importância crucial do processo comunicativo e, daquele, a necessidade de institucionalização da vontade democrática por meio de decisões legislativas (HABERMAS, 1995). 
presente nos ideais republicanos de autodeterminação coletiva. A questão que fica em aberto aqui é a maneira pela qual seria possível ligar o ato de vontade, o voto, ao processo comunicativo necessário à garantia de decisões legítimas. As teses da necessidade identificam a comunicação pública como um processo por meio do qual se definem quais razóes seriam aceitáveis para justificar o uso do poder político. Essas razóes poderiam ser entendidas como um leque de bens que uma associação democrática compartilha num dado momento, sempre aberto a transformaçóes, dentro de certos limites. $\mathrm{O}$ conjunto de razóes legítimas não determina uma opção, mas um leque de opçóes aceitáveis, dentre as quais a agência vai optar por uma. Nesse sentido, o objetivo principal do processo discursivo não é o consenso sobre uma decisão específica, mas ligar a razão pública, que elenca as opçóes razoáveis, à vontade coletiva (ARAÚJO, 2004, p. 165-166).

A questão sobre as condiçôes de possibilidade da democracia consiste, assim, em indagar a respeito de como a racionalidade das práticas argumentativas pode servir como base para a construção de referenciais indispensáveis à continuidade de um sistema democrático ao longo do tempo. O que há de peculiar nessa interpretação não é apenas a necessidade da deliberação per se como prática fundamental à justificação da autoridade. Antes, consiste no objeto a respeito do qual se delibera e nas razôes que são levadas em consideração nas decisões coletivas. As condiçôes necessárias à realização da democracia vão desde exigências de igualdade política até a garantia de direitos substantivos e condições institucionais que vão além das regras procedimentais. Essa perspectiva possui uma forte concepção de inclusão no sentido em que Young (2010) concebe este ideal.

Uma análise mais aprofundada da tese da necessidade poderia demonstrar de que maneira as diversas arenas do sistema democrático desenvolvem códigos e formas de organização distintos, como elas se coordenam e interagem. Tais instâncias, que incluem o Poder Legislativo, as cortes, a sociedade civil organizada, as instituiçôes participativas, os meios de comunicação de massas, entre outros, impóem exigências diferentes em relação à razão pública. Incorporam, além disso, variados requisitos de acesso e condiçóes para o discurso. Não caberia, porém, no escopo deste trabalho, 
um olhar mais detido sobre tais peculiaridades ${ }^{29}$. Cabe assinalar apenas aquilo que parece mais significativo a distingui-la das perspectivas anteriores, a saber, o reconhecimento do caráter deliberativo da autoridade que se constitui na medida em que se exige o oferecimento de razóes para justificar a coerção que ultrapassa a agregação de interesses, ao mesmo tempo em que não se limitam nem às bases éticas de uma comunidade, tampouco à cooperação produzida mediante a participação no processo discursivo.

\section{Considerações finais}

$\mathrm{O}$ artigo que ora se encerra buscou oferecer uma visão abrangente sobre o modo como a teoria democrática lida com a questão de legitimidade política - ou o papel conferido pelas teorias contemporâneas da democracia à comunicação, entendida de forma ampla como "discussão pública", na justificação das decisóes coletivas. Para tanto, buscamos lançar luz sobre a função atribuída à comunicação na justificação da autoridade política em interpretaçóes distintas sobre a ideia de democracia e o seu valor. O tema é, ao mesmo tempo, clássico e atual, na medida em que se dedica a uma questáo perene dentro do arcabouço epistêmico da teoria política a justificação da autoridade - bem como a um problema premente com o qual lidamos no cotidiano de nossas democracias e na teoria política contemporânea - a questão da deliberação pública.

Ao buscar elucidar os fundamentos normativos da legitimidade e o lugar dos processos comunicativos em sua constituição, o texto identifica três tipos de respostas, que, inspirando-me em Christiano (1997), denominei de (a) tese da contribuição, (b) tese da exclusividade e (c) tese da necessidade. Não obstante a dificuldade de situar autores e perspectivas distintas em cada uma das teses apresentadas, pareceu-me possível apresentar a questão a partir de uma controvérsia acerca das condiçóes necessárias e/ou suficientes para se considerar legítima uma decisáo coletiva. Grosso modo, cada uma das teses corresponde, respectivamente, à forma como, primeiramente, as teorias

29 Dryzek (2016) e Elstub, Ercan e Mendonça (20I6) sugerem que estes são os aspectos em que os estudos deliberativos devem se desenvolver em futuro próximo. Procurando incorporar metodologias inovadoras na avaliação dos sistemas deliberativos, aparecem como questões a serem observadas a inserção de arenas não deliberativas, a conexão entre as diversas instâncias que constituem o sistema, entre outras. 
competitivas, em seguida, as teses comunitaristas e participativas, e, por fim, a teoria deliberativa (notadamente em sua geração mais recente) enxergam o lugar da deliberação pública na legitimidade da autoridade política.

Por meio da revisão da literatura, evidenciou-se, de um lado, dois modelos de democracia - a saber, um modelo minimalista e um modelo que poderíamos denominar como republicano e/ou participativo - e, de outro, uma vertente deliberativa da teoria democrática. Enquanto as primeiras estabelecem determinado procedimento, a agregação de preferências, em um caso, e a participação discursiva, no outro, como responsáveis pela legitimidade da autoridade, a última evita situar a legitimidade em apenas um mecanismo de construção de uma ordem democrática. Embora estabeleça a comunicação entre iguais que ocorre na esfera pública e nas diversas instâncias discursivas como componente fundamental da justificação política, ressalta a importância, para o estabelecimento de razóes aceitáveis ao exercício do poder, de outras instâncias deliberativas bem como de outras formas de participação.

$\mathrm{O}$ quadro final apresentado parece-me representativo tanto das formas mais tradicionais de colocar o problema quanto do que de mais inovador tem surgido na literatura da área. Se não foi possível esgotar todos os pontos de vista que se apresentam ao debate, o artigo faz um convite aos que se dedicam, no campo da teoria política, aos problemas de ordem normativa e às questóes presentes no dia a dia das democracias atuais, a pensar o problema da justificação pública das normas e as implicações das formas de comunicação para constituir uma autoridade legítima.

\section{Referências}

ANDERSON, Elizabeth. Democracy: Instrumental vs. Non-Instrumental Value. In: CHRISTIANO, Thomas; CHRISTMAN, John. Contemporary Debates in Political Philosophy. Wiley-Blackwell, Oxford, UK, 2009. p. 213-227

ARAÚJO, Cícero. Razão Pública, bem comum e decisão democrática. In: COELHO, Vera Schattan Ruas Pereira; NOBRE, Marcos (org.). Participaçáo e Deliberaçáo: Teoria democrática e experiências institucionais no Brasil contemporâneo. São Paulo: Editora 34, 2004. p. 157-169.

ARENDT, Hannah. "O que é liberdade?”. In: ARENDT, Hannah. Entre o passado e o futuro. São Paulo: Editora Perspectiva, 2007. p. 189-220. 
ARENDT, Hannah. A Promessa da Política. Organizado por Jerome Kohn; Tradução de Pedro Jorgensen Jr.. Rio de Janeiro: DIFEL, 2008.

BARBER, Benjamin R. Strong Democracy: participatory politics for a new age. Berkeley: University of California Press, 1984.

BELLAH, Robert N. The Good Society. New York: Knopf, 1991.

BERLIN, Isaiah. Two concepts of liberty. In: HARDY, Henry (org.), Liberty. Oxford, 2002. p. 118-172.

BOURDIEU, Pierre. A Economia das Trocas Linguísticas. São Paulo: EDUSP, 2008.

CHAMBERS, Simone. Deliberation and Mass Democracy. In: PARKINSON, John; MANSBRIDGE, Jane (ed.). Deliberative Systems: deliberative democracy at the large scale. Cambridge: Cambridge University Press, 2012. p. 52-71.

CHRISTIANO, Thomas. The Significance of Public Deliberation. In: BOHMANN, James; REGH, William (ed.). Deliberative Democracy: essays on reason and politics. Cambridge, MA: The MIT Press, 1997. p. 243-278.

COHEN, Joshua. Democracy and Liberty. In: ELSTER, Jon (ed.). Deliberative Democracy. Cambridge, MA: Cambridge University Press, 1998. p. 185-231.

COHEN, Joshua. Reflections On Habermas On Democracy. Ratio Juris, v. 12, n. 4, p. 385-416, dec. 1999.

COHEN, Joshua. For a democratic society. In: FREEMAN, Samuel. (org.). The Cambridge Companion to Rawls. Cambridge: Cambridge University Press, 2003. p. 86-138.

DAHL, Robert. Democracy and Its Critics. New Haven: Yale University Press, 1989.

DAHL, Robert. On Political Equality. New Haven: Yale University Press, 2006.

DOWNS, Anthony. Uma Teoria Econômica da Democracia. São Paulo: EDUSP, 1999.

DRYZEK, John S. Legitimidade e economia na democracia deliberativa. In: COELHO, Vera Schattan P.; NOBRE, Marcos (org.). Participaçáo e Deliberaçáo: Teoria Democrática e Experiências Institucionais no Brasil Contemporâneo. São Paulo: Ed. 34, 2004. p. 41-62.

ELSTUB, Stephen; ERCAN, Selen; MENDONÇA, Ricardo Fabrino. Editorial introduction: The fourth generation of deliberative democracy. Critical Policy Studies, v. 10, n. 2, p. 139-151, 2016.

MENDONÇA, Ricardo Fabrino. Antes de Habermas, Para Além de Habermas: uma abordagem pragmatista de democracia deliberativa. Revista Sociedade e Estado, v. 31, n. 3, p. 741-768, set./ dez. 2016.

FORST, Rainer. Contextos da Justiça. Filosofia Política Para Além de Liberalismo e Comunitarismo. São Paulo: Boitempo Editorial, 2010.

FRANCISQUINI, Renato. Democracia, liberdade de expressáo e o valor equitativo das liberdades comunicativas. Orientador: Álvaro de Vita. 2014. 296 f. Tese (Doutorado em Ciência Política) - Departamento de Ciência política, Universidade de São Paulo, São Paulo, 2014. 
HABERMAS, Jürgen. The Structural Transformation of the Public Sphere: an Inquiry into a Category of a Bourgeois Society. Cambridge: MIT Press, 1989.

HABERMAS, Jürgen. Três Modelos Normativos de Democracia. Lua Nova, n. 36, p. 39-53, 1995.

HABERMAS, Jürgen. Direito e Democracia: entre facticidade e validade. Vol. 2. Rio de Janeiro: Tempo Brasileiro, 1997.

KINDER, Donald; SEARS, David. Public Opinion and Political Action. In: LINDZEY, Gardner; ARONSON, Elliot (ed.). Handbook of Social Psychology. $4^{\text {th }}$ ed. New York: Random House, 1985. p. 659-741.

MANIN, Bernard. As metamorfoses do governo representativo. Revista Brasileira de Ciências Sociais, n. 29, p. 5-34, 1995.

MANSBRIDGE, Jane; BOHMAN, James; CHAMBERS, Simone; CHRISTIANO, Thomas; FUNG, Archon; PARKINSON, John; THOMPSON, Dennis; WARREN, Mark. A Systemic Approach to Deliberative Democracy. In: PARKINSON, John; MANSBRIDGE, Jane (ed.). Deliberative Systems: deliberative democracy at the large scale. Cambridge: Cambridge University Press, 2012. p. 1-26.

MILL, John Stuart. A Liberdade. São Paulo: Martins Fontes, 2000.

PATEMAN, Carole. Participaçáo e Teoria Democrática. São Paulo: Paz e Terra, 1992.

PRZEWORSKI, Adam. Deliberation and Ideological Domination. In: ELSTER, Jon. (ed.) Deliberative Democracy. Cambridge, MA: Cambridge University Press, 1998. p. 140-160.

PRZEWORSKI, Adam. Minimalist conception of democracy: a defense. In: SHAPIRO, Ian; HACKER-CORDÓN, Cassiano (ed.). Democracy's Value. Cambridge: Cambridge University Press, 1999. p. 12-17.

PRZEWORSKI, Adam. Democracy and the Limits of Self-Government. New York: Cambridge University Press, 2010.

RAWLS, John. Justice as Fairness - a reestatement. Edited by Erin Kelly. Cambridge, Mass: The Belknap Press of Harvard University Press, 2003.

RAWLS, John. Uma Teoria da Justiça. Tradução de Jussara Simões. 3. ed. São Paulo: Martins Fontes, 2008.

RAWLS, John. O Liberalismo Político. Tradução de Álvaro de Vita. ed. ampl. São Paulo: Editora WMF Martins Fontes, 2011.

ROUSSEAU, Jean-Jacques. Do Contrato Social. Tradução de Antonio Danesi. São Paulo: Martins Fontes, 2006.

SANDEL, Michael. Democracy's Discontent: America in Search of a Public Philosophy. Cambridge, Mass: Belknap Press/Harvard University Press, 1998. 
SARTORI, Giovanni. A Teoria da Democracia Revisitada. Volume I - O Debate Contemporâneo. São Paulo: Ática, 1994.

SCHUMPETER, Joseph. Capitalismo, Socialismo e Democracia. Editado por George Allen e Unwin Ltd.; traduçấo de Ruy Jungmann. Rio de Janeiro: Editora Fundo de Cultura, 1961.

SEARING, Donald D.; SOLT, Frederick; JOHNSTON, Pamela; CREWE, Ivor. Public discussion in the deliberative system: does it make better citizens? British Journal of Political Science, v. 37 , n. 4, p. 587-618, 2007.

SHAPIRO, Ian. The Moral Foundations of Politics. Yale: Yale University Press, 2003.

STOKES, Susan. Pathologies of Deliberation. In: ELSTER, Jon (ed.). Deliberative Democracy. Cambridge, MA: Cambridge University Press, 1998. p. 123-139.

TAYLOR, Charles. Argumentos Filosóficos. São Paulo: Loyola, 2000.

TOCQUEVILLE, Alexis de. Democracy In America. Translated by Arthur Goldhammer. New York: Library of America, Distr. By Penguin Putnam, 2004.

WARREN, Mark E. Deliberative Democracy and Authority. American Political Science Review, v. 90 , n. 1, p. 46-60, march 1996.

WARREN, Mark E. When, Where and Why Do We Need Deliberation, Voting and Other Means of Organizing Democracy? A Problem Based Approach to Democratic Systems. Prepared for the 2012 Annual Meeting of the American Political Science Association. New Orleans, sep. 2012.

YOUNG, Iris Marion. Comunicação e o Outro: Além da Democracia Deliberativa. In: SOUZA, Jessé (org.). Democracia Hoje: novos desafios para a teoria democrática contemporânea, Brasília: Editora Universidade de Brasília, 2001. p. 365-386.

YOUNG, Iris Marion. Inclusion and Democracy. New York: Oxford University Press, 2010. 


\section{Democracy and Legitimacy: three thesis on the role of communication in political justification}

\section{Abstract}

This paper intends to contribute to a broad understanding of the role attributed to communication, by contemporary democratic theory, in the justification of political authority. To achieve this goal, diversified theoretical perspectives will be settled in three groups - the theses of contribution, exclusivity and necessity - according to the place each assigns to deliberation in guaranteeing legitimacy to collective decisions. Based on the review of the relevant literature, a distinction becomes evident in what refers to sufficient and/or necessary conditions for political decisions to be considered by all of those affected as morally acceptable and politically convenient. It rests clear, therefore, a background disagreement in the degree of importance attributed to communication between equals to assure the justification of political authority.

Keywords: Democratic theory. Legitimacy. Communication. 